\title{
5 Research Square

\section{Role of school as a supportive entity for positive oral health behavior among adolescents in Ibadan, south-western Nigeria}

Folake Barakat Lawal ( $\sim$ folakemilawal@yahoo.com )

University of Ibadan https://orcid.org/0000-0002-3193-387X

Gbemisola Aderemi Oke

University of Ibadan College of Medicine

\section{Research article}

Keywords: oral health, health promotion, adolescents, school, school health, behavior change

Posted Date: June 2nd, 2020

DOI: https://doi.org/10.21203/rs.3.rs-21685/v1

License: (c) (i) This work is licensed under a Creative Commons Attribution 4.0 International License.

Read Full License 


\section{Abstract \\ Background}

The school is primed as an avenue for promoting health among adolescents. Conversely, the high unmet dental needs among school-going adolescents raises concern about the role of schools in this task. This study therefore assessed the role of schools in supporting positive oral health behavior of adolescents in a major city in a Low-Income-Country.

\section{Methods}

From 30 secondary schools that were randomly selected, 2097 students aged 12-18 years were recruited for this cross sectional study conducted in Ibadan, Nigeria. Data was obtained through the use of selfadministered questionnaire to the students; this assessed oral health education and other oral health promotional activities that had taken place in the school from the students as well as their motivation to participate in school oral health programme. A checklist was used to assess availability of oral health promotional materials in the schools and the schools' tuck shops for sale of healthy food. Data were analyzed with SPSS.

\section{Results}

The only oral health promotional activity reported in the schools was oral health education conducted in $8(26.7 \%)$ schools and only $331(15.8 \%)$ students had been educated about their oral health. There were no oral health promotional materials in the schools. About half, 1161 (55.4\%) students were motivated to participate in school oral health program. All the tuck shops had cariogenic foods and drinks for sale. Students from schools where oral health education had been conducted were better motivated to participate in school oral health program $(\mathrm{OR}=1.6,95 \% \mathrm{Cl}=1.2-2.0, \mathrm{p}<0.001)$ but disagreed with restriction of sales of cariogenic food in school's stuck shops $(\mathrm{OR}=2.2,95 \% \mathrm{Cl}=1.6-3.0, \mathrm{p}<0.001)$.

\section{Conclusion}

The schools surveyed played very little or no role to support positive oral health behavior of adolescents. Students who had been exposed to oral health education in school were better motivated about their oral health.

\section{Background}

Adolescence is the transition stage between childhood and adulthood. It is a crucial period when the foundations of healthy behavior that linger into adulthood are formed. The school is one of the important avenues for promoting such healthy behavior among a sizeable number of adolescents [1]. Globally, 
school health program has gained popularity in promoting health among children and adolescents [2]. It has been utilized to address various health issues and promote health awareness with positive results on behavior change among other health outcomes [3-7]. Despite, the positive influence that the school has on general health, there is very little documentation of the role schools play in promoting oral health among adolescents globally. This is important in view of the prevalent poor oral hygiene and periodontal diseases among adolescents in many countries [8-12]. This is in spite of the positive effects of oral health education interventions that had been evaluated in schools [13-17]. In addition, many adolescents live with high unmet dental needs, which significantly impact on their quality of life [18]. As such, it is necessary to investigate the role of the school as an entity for oral health promotion among adolescents. Furthermore, understanding and analyzing the factors that could influence behavior, which are peculiar to the oral health of adolescents in schools is imperative. In addition, it will provide information on existing oral health promotion activities and the strengths or deficiencies of such programs in schools. These will serve as baseline information that will guide oral health promotion interventions among adolescents. More so, there is overwhelming evidence of need for school based oral health promotion programs in low income countries [19]. This study therefore assessed the role of schools in supporting positive oral health behavior among adolescents in a low-income country.

\section{Methods}

\section{Study design}

This cross-sectional study was conducted among senior secondary school students in the senior school classes I and II (Grades 10 and 11) in randomly selected secondary schools in Ibadan. Ibadan is the largest city in West Africa and the capital city of Oyo State, Nigeria. There are major tertiary educational and health institutions within the city. The institutions serve as important centers where oral health promotion is organized among adolescents and the general populace. One of the tertiary institutions has an upcoming unit; the school oral health subunit, which used to be part of the oral health promotion unit. The school oral health subunit has a goal of reaching out to children, adolescents, teachers and their families. Part of the initial efforts of the subunit is acquisition of baseline information on existing oral health promotion in schools.

\section{Sample size determination}

Sample size was calculated using sample size formula for observational studies [20] at a power of $80 \%$, prevalence rate of $18.3 \%$ of participation of secondary schools in an audit from a previous study [21] and degree of error of $2 \%$. This was inflated by a non-response rate of $30 \%$ and resulted in a minimum sample size of 2052 students.

\section{Sampling}

The schools included in this study were selected through simple random sampling method in three stages. The first stage involved selection of three Local Government Areas within the metropolis of 
Ibadan using a table of random numbers. The second stage involved selection of 10 schools from each Local Government Area using a table of random numbers. This resulted in the selection of a total number of 30 schools from the list of schools within the metropolis of Ibadan. Seventy students were selected from the class registers of the two classes (senior school classes I and II) in each of the 30 schools using a table of random numbers.

\section{Selection criteria}

Only students who returned signed consent forms, who gave assent to participate in the study and were available at the time of the study were included in the study. Students who had special needs or were ill at the time of visit to their schools were excluded from the study.

\section{Data collection tool}

Data collection tools included structured self-administered questionnaire that was administered to the students and a checklist that was used to assess the school environment for oral health promotional activities and materials. The questionnaire assessed sociodemographic characteristics of the students; the class, age, occupation of parents and educational qualification of parents. The occupation of the parents was classified based on a modification of Office of Population Censuses and Surveys, which had been used previously in this environment $[22,23]$ The higher of the occupational classes for the two parents was recorded for each participant. The questionnaire also assessed if the students had participated in any oral health education programme and other oral health promotional activities in the school. Also assessed was information on the students "perceived benefit from a school oral health education programme if instituted in their school" described as "positive", "negative" or being "indifferent". If they will participate in an oral health promotion programme instituted in their school described as "agree" or "disagree" and if they "agree" or "disagree" with sales of cariogenic food at the tuck shops.

The checklist was used to assess oral health promotional materials available in the school. The checklist was a ten-item tool that was used to assess: the presence or absence of oral health posters, electronic boards displaying oral health information and bill boards. There was a column to record other oral health information display tools. In addition, the checklist assessed the presence or absence of tuck shops within the school or outside the school but within the reach of the students. The items on sale at tuck shops such as fruits, water, sugar containing drinks or cariogenic foods were also checked as being present or not. Also assessed was presence or absence of school dental clinic or bay.

\section{Data analysis}

Data obtained was analyzed with SPSS version 23. Quantitative variable such as age was summarized using mean and standard deviations. Categorical variables were summarized by proportions. Chi-square statistics was used to test for associations between categorical variables such as participation in oral health education in the school and sociodemographic characteristics of the students. Logistic regression 
was used to evaluate predictors of having participated in oral health education in the school and variables assessing motivation of the students. The level of statistical significance was set at $p<0.05$.

\section{Ethical consideration}

Ethical approval for the study was obtained from the State Ethics Review Board. Permission to conduct the study was obtained from the principal of each school. A written consent was obtained from the parents of each student to conform with the State Schools' Board policy, which mandated that consent be obtained from parents before the student participates in the study regardless of the age of the student. In addition, assent was also obtained from the students before recruitment into the study. All participants were given the right to withdraw from the study at any point in time.

\section{Results}

A total of 2100 students were approached for the study, of which 2097 (99.9\%) consented to participate in the study. There were 1126 (53.7\%) males and 971 (46.3\%) females. The mean age of the students was $15.3 \pm 1.4$ years. The majority of their parents, 1809 (86.3\%), belonged to the unskilled occupational class (Table 1).

Table 1

Sociodemographic characteristics of students that participated in the study

\begin{tabular}{|lll|}
\hline Variable & Frequency & $\%$ \\
\hline Gender & & \\
\hline Female & 971 & 46.3 \\
\hline Male & 1126 & 53.7 \\
\hline Age (years) & & \\
\hline $12-15$ & 1285 & 61.3 \\
\hline $16-18$ & 812 & 38.7 \\
\hline Parent's occupational class & & \\
\hline Skilled & 200 & 9.5 \\
\hline Others (unskilled and dependents) & 1897 & 90.5 \\
\hline Previous oral health education & & \\
\hline Yes & 331 & 15.8 \\
\hline No & 1766 & 84.2 \\
\hline
\end{tabular}

The only oral health promotional activity documented was oral health education, which had been conducted in 8 (26.7\%) schools; only 331 (15.8\%) students had been educated about their oral health. 
Teachers $202(61.0 \%)$, dentists $128(38.7 \%)$ and a nurse $1(0.3 \%)$ were the educators. There was no oral health promotional material in any of the schools.

Bivariate analysis showed that a higher proportion of students who were females 172 (17.7\%), 12-15year-old $236(18.4 \%)$, had parents who were skilled workers $48(24.0 \%)$ and had consulted the dentists 27 $(34.2 \%)$ had participated in the school oral health education program than others (Table 2).

Table 2

Bivariate analysis of association between participants' characteristics and school oral health activity

\begin{tabular}{|lllll|}
\hline Student's characteristics & \multicolumn{2}{l}{ School with oral health activity } & $X^{2}$ & P value \\
\hline Age (years) & Yes & No & & \\
\hline $12-15$ & & & & \\
\hline $16-18$ & $236(18.4)$ & $1049(81.6)$ & 16.634 & $<0.001^{*}$ \\
\hline Gender & $95(11.7)$ & $717(88.3)$ & & \\
\hline Female & & & & \\
\hline Male & $172(17.7)$ & $799(82.3)$ & 5.063 & $0.024^{*}$ \\
\hline Occupational class & $159(14.1)$ & $967(85.9)$ & & \\
\hline Skilled & & & & \\
\hline Unskilled & $48(24.0)$ & $152(76.0)$ & 11.972 & $0.003^{*}$ \\
\hline Dependent & $266(14.8)$ & $1537(85.2)$ & & \\
\hline Previous dental consultation & & $77(81.9)$ & & \\
\hline Yes & $17(18.1)$ & & & \\
\hline No & & & & \\
\hline *Statistically significant, $X^{2}$ - Chi square statistics & & & \\
\hline
\end{tabular}

Multivariate analysis showed that students aged 12-15-years $(\mathrm{OR}=1.6, \mathrm{Cl}=1.2-2.1, \mathrm{p}<0.001)$ and had consulted the dentists $(\mathrm{OR}=2.8, \mathrm{Cl}=1.7-4.6, \mathrm{p}<0.001)$ were more likely to participate in school oral health education (Table 3 ). 
Table 3

Multivariate logistic regression analysis of association between oral health activity in schools and participants' characteristics

\begin{tabular}{|c|c|c|c|c|}
\hline Variable & Category & OR & $95 \% \mathrm{Cl}$ & $\mathrm{p}$ value \\
\hline \multicolumn{5}{|c|}{ Age (years) } \\
\hline & $12-15$ & 1.6 & $1.2-2.1$ & $<0.001^{*}$ \\
\hline & $16-18$ & 1.0 & & \\
\hline \multicolumn{5}{|l|}{ Gender } \\
\hline & Female & 1.3 & $1.0-1.6$ & 0.064 \\
\hline & Male & 1.0 & & \\
\hline \multicolumn{5}{|c|}{ Occupational class } \\
\hline & Skilled & 1.3 & $0.7-2.4$ & 0.417 \\
\hline & Unskilled & 0.8 & $0.4-1.3$ & 0.337 \\
\hline & Dependent & 1.0 & & \\
\hline \multicolumn{5}{|c|}{ Previous dental consultation } \\
\hline & Yes & 2.8 & $1.7-4.6$ & $<0.001 *$ \\
\hline & No & 1.0 & & \\
\hline
\end{tabular}

About half 1161 (55.4\%) of the respondents were motivated and will participate in an oral health promotion program while $936(44.6 \%)$ were indifferent or would not participate if an oral health program was instituted. All the schools had tuck shops within the school premises; all had cariogenic foods and drinks, water and fruits for sale. A total of $779(37.1 \%)$ students indicated that cariogenic foods should be restricted from the school's tuck shops, 807 (38.5\%) were indifferent and 511 (24.4\%) disagreed.

Bivariate analysis showed that a higher proportion of students from schools who had been involved in oral health education activities had positive views about oral health 214 (64.7\%) versus 117 (35.3\%) with negative views $\left(X^{2}=13.720, p<0.001\right)$. Many students from schools where oral health education had taken place were indifferent $138(41.7 \%)$ or disagreed $108(32.6 \%)$ about the restriction of sales of cariogenic food and drinks (Table 4). 
Table 4

Association between students' motivation and school oral health activity

\begin{tabular}{|llllll}
\hline \multicolumn{4}{|c}{ School oral health activity } & & \\
Variable & Yes $\mathbf{n}(\%)$ & No $\mathbf{n}(\%)$ & $\mathbf{X}^{2}$ & p value \\
\hline Views about school oral health program & & & & \\
\hline Positive & $214(64.7)$ & $947(53.6)$ & 13.720 & $<0.001^{*}$ \\
\hline Negative & $117(35.3)$ & $819(46.4)$ & & \\
\hline Restriction of sales of cariogenic food & & & & \\
\hline Disagree & $108(32.6)$ & $403(22.8)$ & 25.972 & $<0.001^{*}$ \\
\hline Indifferent & $138(41.7)$ & $669(37.9)$ & & \\
\hline Agree & $85(25.7)$ & $694(39.3)$ & & \\
\hline *Statistically significant, $\quad$ X2- Chi square statistics & & & \\
\hline
\end{tabular}

Logistic regression showed that students who had received oral health education were more likely to have positive views about school oral health program but disagree to restriction of sales of cariogenic food in the tuck shops in schools than those who had not received oral health education hitherto (Table 5). 
Table 5

Logistic regression analysis of association between the students' motivation and participation in school oral health education

\begin{tabular}{|c|c|c|c|c|}
\hline Variable & \multicolumn{2}{|c|}{$\begin{array}{l}\text { School oral health activity } \\
\text { Yes n (\%) No n (\%) }\end{array}$} & \multirow[t]{2}{*}{$x^{2}$} & \multirow[t]{2}{*}{$\mathrm{p}$ value } \\
\hline \multicolumn{3}{|c|}{ Views about school oral health program } & & \\
\hline Positive & $214(64.7)$ & $947(53.6)$ & 13.720 & $<0.001^{*}$ \\
\hline Negative & $117(35.3)$ & $819(46.4)$ & & \\
\hline \multicolumn{5}{|c|}{ Restriction of sales of cariogenic food } \\
\hline Disagree & $108(32.6)$ & $403(22.8)$ & 25.972 & $<0.001^{*}$ \\
\hline Indifferent & $138(41.7)$ & $669(37.9)$ & & \\
\hline Agree & 85 (25.7) & 694 (39.3) & & \\
\hline Variable & Category & OR & $95 \% \mathrm{Cl}$ & $p$ value \\
\hline \multicolumn{5}{|c|}{ Restriction of sales of cariogenic food } \\
\hline & Disagreed & 2.2 & $1.6-3.0$ & $<0.001^{*}$ \\
\hline & Indifferent & 1.6 & $1.2-2.2$ & $0.001 *$ \\
\hline & Agreed & 1.0 & & \\
\hline \multicolumn{5}{|c|}{ Views about school oral health program } \\
\hline & Positive & 1.6 & $1.2-2.0$ & $<0.001^{*}$ \\
\hline & Negative & 1.0 & & \\
\hline
\end{tabular}

\section{Discussion}

The present study assessed the roles of schools in supporting positive oral health behavior among adolescents in selected secondary schools in a metropolis in Nigeria. Our findings showed that the only oral health promotion activity in the schools was oral health education. The finding highlights gross deficiencies of the schools in promoting oral health among adolescents. It also contrasts other findings where supervised school brushing, preventive services and treatment services among other activities are components of the school oral health program [24-26]. It is also noteworthy that less than $30 \%$ of the schools had benefitted from such programs and about $20 \%$ of the students had participated in such programs. This contrast findings from countries like Kuwait [25] and developed countries where school oral health has gained prominence and covered many schools in the districts and the country at large [26]. Teachers were the main educators of oral health in the schools with dentists coming next. This is not 
surprising as teachers are expected to pass across health information in schools more so, they are the ones in close contact with the students throughout the school period. This was similarly documented in a previous report [26].

Dentists as educators in schools supports previous studies on the role of public health dentists in school oral health education [21]. There are few public health dentists in the country [27] and hence limited coverage of the schools. Training of more public health dentists is one solution to the present problem but it would take a long time and enormous resources to have the right number required for the school population. The training of personnel to complement oral health promotion in schools is, therefore, worthwhile and teachers can fit this role.

None of the schools had oral health promotional materials in place for the students to learn from or serve as a reminder on daily basis. Consistency is important in instilling knowledge for positive attitude and behavior change [14]. In addition, written communication has also been found helpful in behavior change [28]. Therefore, the need for oral health promotional materials such as posters among others in schools in the country is pertinent. Importantly, provision of the materials will have to be looked into for prospects and success of oral health promotion interventions. Furthermore, production of oral health education materials on a large scale for all schools to improve awareness should be considered. In addition, it will contribute to educative opportunities in which good oral health behavior can be developed and sustained, thus encouraging to the students. All the tuck shops in the schools had fruits and cariogenic food on their shelves. Although the availability of fruits is a positive effort, this is countered by the continuous supply of cariogenic food. Appropriate intervention to this effect may go a long way in restricting its sale and thus limiting the negative influence that its availability may have on the students' behavior.

This is further buttressed by the fact that the majority of the students did not want restriction of sales of cariogenic food in the school's tuck shops. In fact, students from schools that had conducted oral health education program were more likely to disagree with the restriction of sales of cariogenic diet in the school's tuck shop. This is a pointer to inadequate motivation despite oral health education program conducted in their schools. Absence of promotional materials may have contributed to this. In addition, the students may fear that the school may enforce restriction of sales of cariogenic food if students are committed to a restriction. School policy on restriction of sale of cariogenic food will also go a long way in providing supportive environment for oral health promotion in the schools. Policy as facilitating factor for sustainable school oral health program has been documented [26]. In addition, those who had participated in the school oral health program were more likely to have consulted a dentist. This can be alluded to the motivation of students to seek dental care from messages learnt during the oral health education programs. This is encouraging as the school oral health education program can be an avenue to encourage students to utilize dental services.

A higher proportion of students that that had participated in oral health education in schools were motivated to participate in subsequent school oral health program. Availability of oral health promoting opportunities in schools such as school dental club and school dental clinic among others will go a long 
way in impacting the students' behavior positively and a higher likelihood of being motivated for a positive behavior change. However, in the schools that were studied, only a few had exposed their students to oral health education, there were inadequate oral health promotional activities and lack of oral health promotional materials.

The study has a major limitation: that it was conducted among public school students only. This may affect generalizability of findings to private schools in the country. However, this was done as school oral health programs will be initiated in public schools as their attendees suffer more often from preventable oral diseases of significant concern in LMICs.

In conclusion, the schools surveyed played very little or no role to support positive oral health behavior of adolescents. There were no oral health promotional materials in the schools. Students who had been exposed to oral health education in school were better motivated about their oral health.

\section{Abbreviations}

$\mathrm{Cl}$ - Confidence interval

LMIC - Low and middle income countries

OR - Odds ratio

\section{Declarations}

\section{Ethics approval and consent to participate}

Ethical approval for the study was obtained from the Oyo State Ethics Review Board. Permission to conduct the study was obtained from the principal of each school. A written consent was obtained from the parents of each student. Assent was also obtained from the students before recruitment into the study.

\section{Consent for publication}

Not applicable

\section{Availability of data and materials}

The datasets used and/or analyzed during the current study are available from the corresponding author on reasonable request.

\section{Competing interests}


The authors declare that they have no competing interests.

\section{Funding}

This research was supported by the Consortium for Advanced Research Training in Africa (CARTA). CARTA is jointly led by the African Population and Health Research Center and the University of the Witwatersrand and funded by the Carnegie Corporation of New York (Grant No--B 8606.R02), Sida (Grant No:54100113), the DELTAS Africa Initiative (Grant No: 107768/Z/15/Z) and Deutscher Akademischer Austauschdienst (DAAD). The DELTAS Africa Initiative is an independent funding scheme of the African Academy of Sciences (AAS)'s Alliance for Accelerating Excellence in Science in Africa (AESA) and supported by the New Partnership for Africa's Development Planning and Coordinating Agency (NEPAD Agency) with funding from the Wellcome Trust (UK) and the UK government. The statements made and views expressed are solely the responsibility of the Fellow".

Support was also obtained from the TetFund Institutional Based Research Grant, Nigeria.

\section{Authors' contributions}

FBL conceptualized the study, wrote the proposal for the study, designed the study instrument, coordinated data collection and analysis and wrote the first draft of the manuscript. GAO contributed to the study proposal, the design of the study instrument and parts of the manuscript. Both authors read and approved the final version of the manuscript.

\section{Acknowledgements}

Many thanks to Dr. T.A Lawal for the statistical inputs.

\section{References}

1. World Health Organization. Promoting health through schools: report of a WHO expert committee on comprehensive school health education and promotion. Geneva: World Health Organization; 1997.

2. McNeely CA, Nonnemaker JM, Blum RW. Promoting school connectedness: Evidence from the national longitudinal study of adolescent health. J Sch Health. 2002;72:138-46.

3. World Health Organization. Healthy nutrition: an essential element of a health-promoting school. Geneva: World Health Organization; 1998.

4. Paul-Ebhohimhen VA, Poobalan A, Van Teijlingen ER. A systematic review of school-based sexual health interventions to prevent STI/HIV in sub-Saharan Africa. BMC Public Health. 2008;8:4.

5. Sani AS, Abraham C, Denford S, Ball S. School-based sexual health education interventions to prevent STI/HIV in sub-Saharan Africa: a systematic review and meta-analysis. BMC Public Health. 
2016;16:1069.

6. Turunen $\mathrm{H}$, Sormunen M, Jourdan D, Von Seelen J, Buijs G. Health promoting schools-a complex approach and a major means to health improvement. Health Promot Int. 2017;32:177-84.

7. Weist MD, Bruns EJ, Whitaker K, Wei Y, Kutcher S, Larsen T, et al. School mental health promotion and intervention: Experiences from four nations. School Psychology International. 2017;38:343-62.

8. Bendoraitienè E, Zūbienè J, Vasiliauskienè I, Saldūnaitè K, Andruškevičienė V, Basevičienè N, et al. Periodontal status in 18-year-old Lithuanian adolescents: An epidemiological study. Medicina. 2017;53:253-8.

9. Botero JE, Rösing CK, Duque A, Jaramillo A, Contreras A. Periodontal disease in children and adolescents of Latin America. Periodontol 2000. 2015;67:34-57.

10. Ericsson JS, Abrahamsson KH, Ostberg A-L, Hellström M-K, Jönsson K, Wennström JL. Periodontal health status in Swedish adolescents: an epidemiological, cross-sectional study. Swed Dent J. 2009;33:131-9.

11. Popoola BO, Dosumu EB, Ifesanya JU. Periodontal status and treatment need among adolescents in Ibadan, Southwestern Nigeria. Braz J Oral Sci. 2015;14:117-21.

12. Chen X, Ye W, Zhan JY, Wang X, Tai BJ, Hu DY, et al. Periodontal Status of Chinese Adolescents: Findings from the 4th National Oral Health Survey. Chin J Dent Res. 2018;21:195-203.

13. Esan A, Folayan MO, Egbetade GO, Oyedele TA. Effect of a school-based oral health education programme on use of recommended oral self-care for reducing the risk of caries by children in Nigeria. Int J Paediatr Dent. 2015;25:282-90.

14. Haleem A, Khan MK, Sufia S, Chaudhry S, Siddiqui MI, Khan AA. The role of repetition and reinforcement in school-based oral health education-a cluster randomized controlled trial. BMC Public Health. 2015;16:2.

15. Haque SE, Rahman M, Itsuko K, Mutahara M, Kayako S, Tsutsumi A, et al. Effect of a school-based oral health education in preventing untreated dental caries and increasing knowledge, attitude, and practices among adolescents in Bangladesh. BMC Oral Health. 2016;16:44.

16. Shenoy RP, Sequeira PS. Effectiveness of a school dental education program in improving oral health knowledge and oral hygiene practices and status of 12-to 13-year-old school children. Indian J Dent Res. 2010;21:253.

17. Yekaninejad MS, Eshraghian MR, Nourijelyani K, Mohammad K, Foroushani AR, Zayeri F, et al. Effect of a school-based oral health-education program on I ranian children: results from a group randomized trial. Eur J Oral Sci. 2012;120:429-37.

18. Lawal FB, Ifesanya JU. Oral Health Impact Profile (OHIP-14) and its association with dental treatment needs of adolescents in a rural Nigerian community. Braz J Oral Sci. 2017;15:215-20.

19. Lawal FB, Taiwo JO. Making a Case for Formal School-Based Oral Health Promotion: Oral Health Knowledge, Attitude and Practices of Pupils in Ibadan, Nigeria. Int Q Community Health Educ. 2018;38:99-105. 
20. Kish L. Survey Sampling. New York: John Wiley and Sons, Inc; 1965.

21. Lawal FB, Taiwo JO. An audit of school oral health education program in a developing country. J Int Soc Prev Community Dent. 2014;4:49-55.

22. Esan TA, Olusile AO, Akeredolu PA, Esan AO. Socio-demographic factors and edentulism: the Nigerian experience. BMC Oral Health. 2004;4:3.

23. Lawal FB, Arowojolu MO. Sociodemographic Status of Patients Seeking Routine Scaling and Polishing in a Resource Challenged Environment. West Afr J Med. 2015;34:193-6.

24. Alsumait A, ElSalhy M, Behzadi S, Raine KD, Gokiert R, Cor K, et al. Impact evaluation of a schoolbased oral health program: Kuwait National Program. BMC oral health. 2019;19:202.

25. Ariga J, Al-Mutawa S, Nazar H. School Oral Health Program in Kuwait. Med Princ Prac. 2014;23S:436.

26. Jurgensen N, Petersen PE. Promoting oral health of children through schools-results from a WHO global survey 2012. Community Dent Health. 2013;30:204-18.

27. Adeniyi AA, Sofola 00 , Kalliecharan RV. An appraisal of the oral health care system in Nigeria. Int Dental J. 2012;62:292-300.

28. Michie S, Johnston M. Changing clinical behaviour by making guidelines specific. BMJ. 2004;328:343-5. 